\title{
A Study on Productivity Improvement for the SKD11 Steel Grinding by Using CBN Grinding Wheel - A New Approach
}

\author{
Nguyen Hong Son ${ }^{1, *}$, Do Duc Trung ${ }^{2}$, Nhu-Tung Nguyen ${ }^{2}$ \\ ${ }^{1}$ Center for Mechanical Engineering, Hanoi University of Industry, Vietnam \\ ${ }^{2}$ Faculty of Mechanical Engineering, Hanoi University of Industry, Vietnam
}

Received November 8, 2019; Revised December 9, 2019; Accepted December 17, 2019

Copyright $\subseteq 2020$ by authors, all rights reserved. Authors agree that this article remains permanently open access under the terms of the Creative Commons Attribution License 4.0 International License

\begin{abstract}
This paper presents a new approach to improve the machining productivity when grinding the SKD11 steel by using CBN grinding wheel. This approach based on the satisfaction of the surface roughness requirement. The grinding experiments were carried out according to Box-Behnken plan by using the CBN grinding wheel, HY-180x13x31.75-100\#. The experimental data was used to build a regression function of the surface roughness depending of the cutting parameters in grinding process including the workpiece velocity, radial feed rate, and depth of cut. The effect degree of each cutting parameter on the surface roughness was also determined. And then, a new solution was proposed to improve the grinding productivity by increasing the workpiece velocity with the satisfaction of the surface roughness requirement. The proposed solution was verified by experimental research. The analyzed results showed that the workpiece velocity can be increased about 1.7 times to increase the machining productivity while the surface roughness only changed about $0.14 \mu \mathrm{m}$.
\end{abstract}

Keywords Surface Grinding, SKD11 Steel, Surface Roughness, Improve Grinding Productivity

\section{Introduction}

In machining processing, the grinding is often a selected method to machine the surfaces with high accuracy and surface gloss. In the studies on the grinding methods, in addition to find the methods on the improvement of surface quality, especially on reducing the surface roughness, the scientists often focus on the methods to improve the productivity in the grinding processes. Many studies that were performed to reduce surface roughness and improve the productivity of grinding process have been published.

Ganesan et al. [1], Rudrapati et al. [2] determined the optimal values of the cutting speed, feed rate, and depth of cut when grinding the 304 stainless steel. The optimal values of the cutting speed, feed rate, and the depth of cut were determined to machine the parts with a small value of surface roughness when grinding the C40E steel [3]. The optimal values of the cutting speed, depth of cut, and number of pass that were determined when grinding OHNS mold steel [4].

Kiyak et al. [5] built the relation between surface roughness and the cutting speed and the feed rate when grinding AISI1050 steel by using the SiC grinding wheel with grain size 60 . This relation was used to determine the cutting speed and the feed rate according to specific surface roughness requirements. Determination of the optimal values of the cutting speed, feed rate, and the depth of cut that was performed to obtain the smallest value of the surface roughness when grinding the ШX15 steel by using Hai Duong grinding wheel [6].

Kumar et al. [7] determined the effect degree of the cutting speed, workpiece velocity, depth of cut, grain size, flow of coolant, and the number of grinding strokes on the surface roughness and the material removal rate when grinding the EN-47 steel by using the $\mathrm{Al} 2 \mathrm{O} 3$ grinding wheel with three different grain sizes of 36, 46, and 60 . These relations were the basis for determination of the machining parameters to reduce surface roughness and improve the machining productivity.

In order to obtain the smallest surface roughness and the highest machining productivity, the cutting speed, feed rate, and depth of cut were determined when grinding the En-19 steel with different hardness states (30, 40 and 50HRC) [8]. Mekala et al. [9] determined the cutting speed, feed rate, and depth of cut to obtain the maximum value of the material removal rate when grinding the AISI 316 steel. 
Based on the above studies, it can be seen that there are many studies that were carried out to determine the machining parameter (cutting speed, feed rate, and the depth of cut), and to machine the parts with a small surface roughness and high machining productivity. However, in these studies, the values of the cutting parameters were only suitable for each specific case. And it is difficult to apply them into the machining the different materials by using the different types of the grinding wheel. Furthermore, in these studies, for each case, usually, only one set of cutting mode values was proposed to ensure the smallest surface roughness, or to achieve the highest machining productivity. In fact, the relationship between cutting parameters and surface roughness was determined from experimental data. According to this relationship, more than one set of cutting parameters can be determined with the constant or almost constant surface roughness values. The grinding productivity that was obtained when applying these set of values can be much different.

In this study, the experiments were carried out when grinding the SKD11 steel to build regression function that was the relationship between the surface roughness and machining parameters including the workpiece velocity, feed rate, and depth of cut. And then, the regression model was analyzed to determine the value machining parameters for improvement of the machining productivity while satisfying surface roughness requirements.

\section{Experimental Method}

\subsection{Testing Machine}

The experiments are conducted on the Toyoda surface grinder - Taiwan as shown in Figure 1.

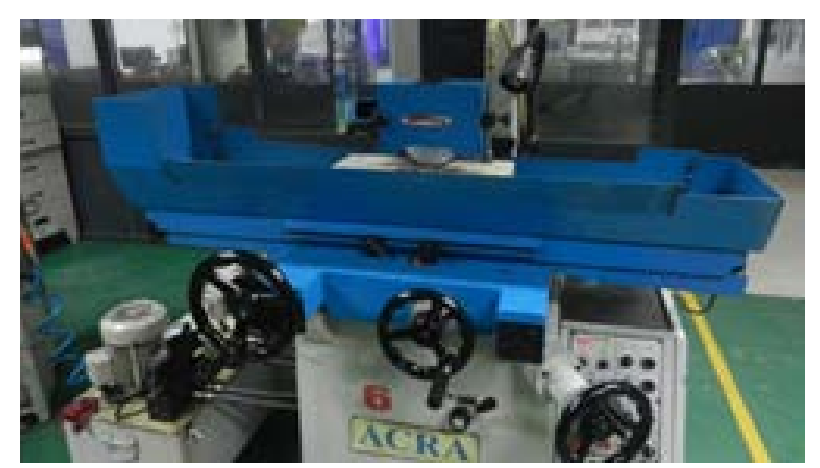

Figure 1. Testing machine

\subsection{Test Workpiece}

The material that was used for grinding experiments was SKD11 steel. SKD11 is a steel grade representing the high alloy steel group that widely is used to manufacture the machine parts with high precision and high surface gloss by using the grinding technology. The equivalent symbols of this steel grade for some countries are presented in Table 1. The workpiece has the dimensions: length $\mathrm{x}$ width $\mathrm{x}$ height of 50 x 40 x 10 (mm), respectively.

Table 1. Symbols equivalent to SKD11 steel grades in some countries

\begin{tabular}{|c|c|c|}
\hline Japan & Russia & America \\
\hline SKD11 & X12M & D2 \\
\hline
\end{tabular}

\subsection{Grinding Wheel}

The grinding wheel that was used in this study was the CBN grinding wheel (Korea), HY-180x13x31.75-100\#.

\subsection{The Surface Roughness Tester}

The surface roughness values were measured by the TESA - rugosuft 10-G. For each experiment, the surface roughness was measured at least 3 times. Surface roughness value at each experimental point was the average value of successive measurements

\subsection{The Experimental Plan}

The experimental plan was designed according to the Box-Behnken plan type that includes the number and the sequence of experiments.

The experimental plan was designed with 3 input parameters including the workpiece velocity, feed rate, and depth of cut. During the experimental, each parameter will receive 3 levels of coded values. The actual value of each parameter at the coding levels was stored in Table 2. The experimental matrix of this study was listed in Table 3.

Table 2. Input parameters and code levels

\begin{tabular}{|c|c|c|c|c|}
\hline \multirow{2}{*}{ Parameters } & \multirow{2}{*}{ Codes } & \multicolumn{3}{|c|}{ Actual values and code levels } \\
\cline { 3 - 5 } & & -1 & 0 & 1 \\
\hline $\mathrm{v}(\mathrm{m} / \mathrm{min})$ & $\mathrm{x}_{1}$ & 5 & 10 & 15 \\
\hline $\mathrm{f}(\mathrm{mm} / \mathrm{stroke})$ & $\mathrm{x}_{3}$ & 3 & 4 & 5 \\
\hline $\mathrm{t}(\mathrm{mm})$ & $\mathrm{x}_{2}$ & 0.01 & 0.015 & 0.02 \\
\hline
\end{tabular}


Table 3. Experimental matrix

\begin{tabular}{|c|c|c|c|c|c|c|c|}
\hline \multirow{3}{*}{ No. } & \multicolumn{6}{|c|}{ Cutting parameters } & \multirow{3}{*}{$\mathrm{R}_{\mathrm{a}}(\mu \mathrm{m})$} \\
\hline & \multicolumn{3}{|c|}{ Actual values } & \multicolumn{3}{|c|}{ Code values } & \\
\hline & $\begin{array}{c}\mathrm{v} \\
(\mathrm{m} / \mathrm{min})\end{array}$ & $\begin{array}{c}\mathrm{f} \\
(\mathrm{mm} / \mathrm{stroke})\end{array}$ & $\begin{array}{c}\mathrm{t} \\
(\mathrm{mm})\end{array}$ & $\mathrm{x}_{1}$ & $\mathrm{x}_{2}$ & $\mathrm{x}_{3}$ & \\
\hline 1 & 5 & 3 & 0.015 & -1 & -1 & 0 & 0.46 \\
\hline 2 & 15 & 3 & 0.015 & 1 & -1 & 0 & 0.75 \\
\hline 3 & 5 & 5 & 0.015 & -1 & 1 & 0 & 0.82 \\
\hline 4 & 15 & 5 & 0.015 & 1 & 1 & 0 & 0.68 \\
\hline 5 & 5 & 4 & 0.010 & -1 & 0 & -1 & 0.59 \\
\hline 6 & 15 & 4 & 0.010 & 1 & 0 & -1 & 0.66 \\
\hline 7 & 5 & 4 & 0.020 & -1 & 0 & 1 & 0.82 \\
\hline 8 & 15 & 4 & 0.020 & 1 & 0 & 1 & 0.80 \\
\hline 9 & 10 & 3 & 0.010 & 0 & -1 & -1 & 0.55 \\
\hline 10 & 10 & 5 & 0.010 & 0 & 1 & -1 & 0.65 \\
\hline 11 & 10 & 3 & 0.020 & 0 & -1 & 1 & 0.62 \\
\hline 12 & 10 & 5 & 0.020 & 0 & 1 & 1 & 0.66 \\
\hline 13 & 10 & 4 & 0.015 & 0 & 0 & 0 & 0.54 \\
\hline 14 & 10 & 4 & 0.015 & 0 & 0 & 0 & 0.52 \\
\hline 15 & 10 & 4 & 0.015 & 0 & 0 & 0 & 0.55 \\
\hline
\end{tabular}

\section{Experimental Results and Discussions}

\subsection{Regression of the Surface Roughness}

The experimental results were stored in Table 3. From the experimental data, the regression model of the surface roughness that depended on the machining parameters (workpiece velocity, feed rate, and depth of cut) in the code form was determined and described by (1). This regression equation has a determination coefficient $R^{2}=0.915$. This value is very close to the 1 . So, this result affirmed that the regression (1) has a very high compatibility with the experimental data.

$$
\begin{array}{r}
Y=R_{a}=0.5377+0.0247 * x_{1}+0.0562 * x_{2}+ \\
0.0579 * x_{3}+0.1187 * x_{1}^{2}+0.0201 * x_{2}^{2}+0.0619 * \\
x_{3}^{2}-0.1066 * x_{1} * x_{2}-0.0233 * x_{1} * x_{3}-0.0130 * \\
x_{2} * x_{3}
\end{array}
$$

The ANOVA analysis was carried out and the analyzed results are listed in Table 4. From this table, it can be seen that when setting the significance level $\alpha=0.05$. The sum of squares between the groups (Regression), $\mathrm{R}$ has a value of 0.1678 , and the sum of squares in the group (Residual error) has a value of $0.0157 . \mathrm{M}$ is the mean square that reflects the ratio between the sum of squares and the degrees of freedom. The critical value that was obtained from the distribution table F, with F-tab $=$ F0.05 $=F(9.3)=$ 0.0032 . Because $\mathrm{F}=5.9522$ which was much larger than $\mathrm{F}$-tab $=0.0032$, it is strongly to affirm that the (1) is highly reliable.
Table 4. ANOVA analysis of the regression model

\begin{tabular}{|c|c|c|c|c|c|}
\hline & $\begin{array}{c}\text { Degree of } \\
\text { freedom }\end{array}$ & S & M & F & F-tab \\
\hline Regression & 9 & 0.1678 & 0.0186 & 5.9522 & 0.0032 \\
\hline $\begin{array}{c}\text { Residual } \\
\text { error }\end{array}$ & 5 & 0.0157 & 0.0031 & & \\
\hline SUM & 14 & 0.1835 & & & \\
\hline
\end{tabular}

From (1), the regression coefficient of $x_{1}$ was 0.024 that is much smaller than the regression coefficients of $x_{2}$ and $x_{3}$ (0.0562 and 0.0579 , respectively). This proved that the effect degree of $x_{1}$ on $\mathrm{Ra}$ is much smaller than the effect degree of $x_{2}$ and $x_{3}$ on that one. To strongly affirm this remark, the surveys on the effect of each cutting parameter on the surface roughness were conducted. Basing on the regression (1), to investigate the effect of a certain factor on the surface roughness, the two remaining factors will be fixed. For example, when fixing two of the three parameters at the coding level 0 , the regression equation that described the effect of each parameter on the surface roughness were presented in (2), (3) and (4). And in these cases, the relationships between the surface roughness and the machining parameters were shown in Figure 2.

$$
\begin{gathered}
y_{1(0)}=0.5377+0.0247 * x_{1}+0.1187 * x_{1}^{2} \\
y_{2(0)}=0.5377+0.0562 * x_{2}+0.0201 * x_{2}^{2} \\
y_{3(0)}=0.5377+0.0579 * x_{3}+0.0619 * x_{3}^{2}
\end{gathered}
$$

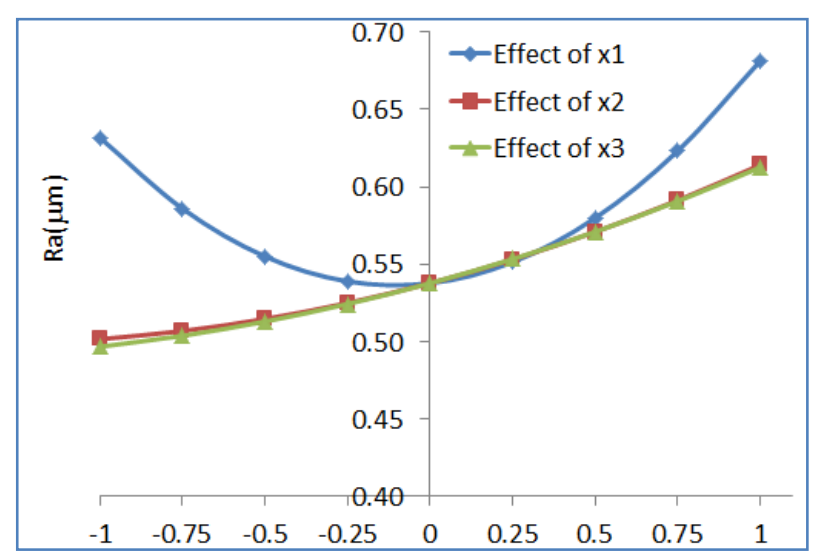

Figure 2. Sub-regression model curves when two of the three parameters are at the coding level 0

Figure 2 showed that the effect of workpiece velocity on the surface roughness was less than the effect of feed rate and depth of cut on that one. This conclusion re-affirmed the above analyzed results. According to this conclusion, in order to change the surface roughness in a narrow range, the feed rate and cutting depth can only be changed in a narrow range, while the workpiece velocity may change in a wider range.

According to Brian Rowe [10], in the surface grinding, the cutting capacity that was defined as the amount of material removed in a unit of time was determined by (5).

$$
Q=b_{w} \cdot t \cdot v
$$


Where $b_{w}, t, v$ bware the contacted length of the workpiece surface and the grinding wheel (usually equivalent to the grinding wheel's thickness), depth of cut, and workpiece velocity, respectively.

From the (5) and the above analysis, the workpiece velocity can be increased to improve the grinding productivity with the small change of the surface roughness value.

\subsection{Determination of Cutting Parameters for Improvement of Machining Productivity}

In order to determine the change range of the workpiece velocity with keeping the surface roughness value at a low level, first of all, from the regression (1), the optimal problem that was used for determination of the cutting mode with the minimum surface roughness was performed. The optimal problem was rewritten in the coded form of the input parameters as described by (6).

$$
\left\{\begin{array}{c}
R_{a}=f\left(x_{1}, x_{2}, x_{3}\right) \rightarrow \text { min } \\
-1 \leq x_{1}, x_{2}, x_{3} \leq 1 \\
R_{a}>0
\end{array}\right.
$$

The genetic algorithm has been used to solve the optimal problem in (2), with the values of algorithm parameters including the number of populations, hybrid probability, and the mutation probability were selected basing on the study of Khoi et al. [11] and Saravanan et al. [12]. These parameters were chosen and listed in Table 5 . The solved results of optimal problem were also presented in Table 5. The graph of the adaptive function was described in Figure 3.

Table 5. Value of parameters when solving the optimal problems by GA

\begin{tabular}{|c|c|}
\hline Number of populations & 150 \\
\hline Hybrid probability & 0,25 \\
\hline Mutation probability & 0,05 \\
\hline $\mathrm{x}_{1}$ & -0.4787 \\
\hline $\mathrm{x}_{2}$ & -1 \\
\hline $\mathrm{X}_{3}$ & 0.7578 \\
\hline $\mathrm{R}_{\mathrm{a}}(\mu \mathrm{m})$ & 0.4429 \\
\hline
\end{tabular}

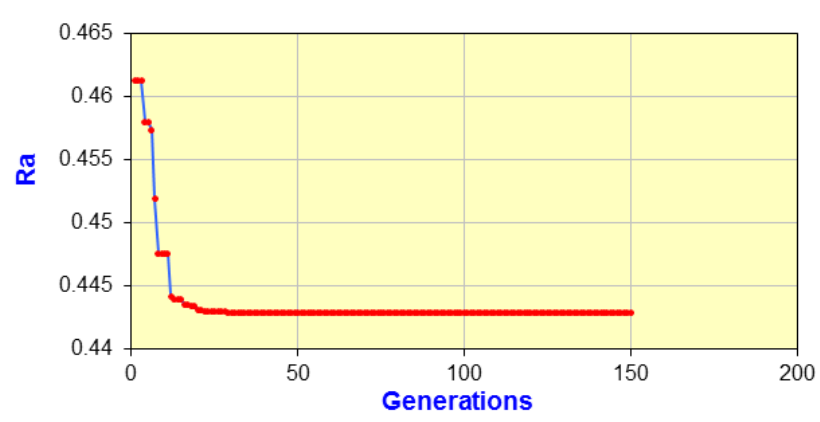

Figure 3. Graph of the adaptation function
Based on the data in Table 5, the optimal valued of the workpiece velocity, feed rate, and depth of cut were 7.6 $(\mathrm{m} / \mathrm{min}), 3(\mathrm{~m} / \mathrm{stroke})$, and $0.017(\mathrm{~mm})$, respectively. In this case, according to the theoretical optimal results, the obtained surface roughness was a minimum value of 0.44 $\mu \mathrm{m}$.

The grinding experimental was conducted with the optimal values of the feed rate and the depth of cut as the above mentions, and with the workpiece velocity changed in some cases as described in Table 6. The measured results of surface roughness in grinding tests were listed in this table.

Table 6. Surface roughness values when grinding tests

\begin{tabular}{|c|c|c|c|c|}
\hline No. & $\mathrm{v}(\mathrm{m} / \mathrm{min})$ & $\mathrm{f}(\mathrm{mm} /$ stroke $)$ & $\mathrm{t}(\mathrm{mm})$ & $\mathrm{Ra}(\mu \mathrm{m})$ \\
\hline 1 & 7.6 & 3 & 0.017 & 0.47 \\
\hline 3 & 9 & 3 & 0.017 & 0.48 \\
\hline 5 & 11 & 3 & 0.017 & 0.53 \\
\hline 7 & 13 & 3 & 0.017 & 0.61 \\
\hline 9 & 15 & 3 & 0.017 & 0.73 \\
\hline
\end{tabular}

The results in Table 6 showed that when the workpiece velocity increased by about 1.7 times (from 7.6 to 13 $\mathrm{m} / \mathrm{min}$ ), the surface roughness only changed by about 0.14 $\mu \mathrm{m}$. So, according to (5), the workpiece velocity can be increased by 1.7 times to increase the grinding productivity by 1.7 times with the change of the surface roughness was only about $0.14 \mu \mathrm{m}$

\section{Conclusions}

From the analyzed results in this study, in the grinding process of the SKD11 steel by using the CBN grinding wheel, the conclusions were given as follows.

A new approach that was used to determine the change range of machining parameters for improvement of machining productivity with the small change of the surface roughness was proposed in this study. The experimental results have shown that the workpiece velocity could be increased by about 1.7 times to increase the grinding productivity by 1.7 times with the quite small change of the surface roughness.

The optimal values of the cutting parameters that was used to machine the workpiece surface with the lowest level were the workpiece velocity of $7.6(\mathrm{~m} / \mathrm{min})$, the feed rate of $3(\mathrm{~m} / \mathrm{stroke})$, and the depth of cut of $0.017(\mathrm{~mm})$.

The optimal grinding parameters that can be used to machine the SKD11 steel with the largest machining productivity while ensuring a small rough surface were the workpiece velocity of $13(\mathrm{~m} / \mathrm{min})$, the feed rate of 3 (mm/stroke), and the depth of cut of $0.017(\mathrm{~mm})$. 


\section{REFERENCES}

[1] M. Ganesan, S. Karthikeyan and N. Karthikeyan, Prediction and Optimization of Cylindrical Grinding Parameters for Surface Roughness Using Taguchi Method, IOSR Journal of Mechanical and Civil Engineering - International Conference on recent trends in engineering and management, pp. 39-46.

[2] Ramesh Rudrapati, Asish Bandyopadhyay, Pradip Kumar Pal, Multi-objective optimization in traverse cut cylindrical grinding, Advanced Materials Manufacturing \& Characterization, vol 3, Issue 1, pp. 335-340.

[3] Naresh Kumar, Himanshu Tripathi, Sandeep Gandotra, Optimization of cylindrical grinding process parameters on C40E steel using Taguchi technique, Int. Journal of Engineering Research and Applications, vol. 5, Issue 1 (Part 3), pp. 100-104.

[4] M.Melwin Jagadeesh Sridhar, M. Manickam, V. Kalaiyarasan, M. Abdul Ghani Khan, and Ttm.Kannan, Optimization of cylindrical grinding process parameters of OHNS Steel (AISI 0-1) rounds using design of experiments concept, International Journal of Engineering Trends and Technology (IJETT), vol. 17, no. 3, pp. 109-114.

[5] M. Kiyak, O. Cakir, E. Altan, A study on surface roughness in external cylindrical grinding, in Proc 12th international scientific Conf Achievements in mechanical \& materials engineering, pp. 459-462.

[6] Dung H. T., Trung. D. D, Thien N. V., Tung N. N., Cuong N., Optimization cutting parameters when grinding WX15 steel using Hai Duong grinding wheel, International Journal of Mechanical and Production Engineering Research and Development, vol. 9, Issue 4, pp. 155-162.

[7] Mukesh Kumar, Sukhjinder Singh, KhushdeepGoyal, To study effect of grinding parameters on surface roughness and material removal rate of cylindrical grinding heated EN47 steel, Journal of Mechanical Engineering, vol. ME 45, no. 2, pp. 81-88.

[8] Rupesh J. Karande, S.M. Jadhav, Kshitij R. Patil, R. K. Nanwatkar, Optimization of Cylindrical grinding machine parameters for minimum surface roughness and maximum MRR, Global research and Development journal for engineering, vol. 2, Issue 5, pp. 62-68.

[9] K Mekala, J Chandradas, K Chandrasekaran, T T M Kannan, $\mathrm{E}$ Ramesh and $\mathrm{R}$ Narasing Babu, Optimization of cylindrical grinding parameters of austenitic stainless steel rods (AISI 316) by Taguchi method, International journal of mechanical engineering and Robotics Research, pp. 208 215.

[10] W. Brian Rowe, Principles of Modern Grinding Technology - 2nd Edition, 2014, https://doi.org/10.1016/C2013-0-0695 $2-6$

[11] Khoi P. B., Trung D. D., Cuong N., Man N. D., Research on Optimization of Plunge Centerless Grinding Process using Genetic Algorithm and Response Surface Method, International Journal of Scientific Engineering and Technology, vol 4, Issue 3, pp.207-211.

[12] Saravanan R, Sachithanandam M., Genetic Algorithm (GA) for Multivariable Surface Grinding Process Optimisation Using a Multi - objective function model, International
Journal of Advanced Manufacturing Technology, pp. 330-338 